\title{
COMUNICACIONES
}

\section{Sobre espías y revoluciones en el Río de La Plata}

\author{
Daniel Lvovich
}

UNGS - CONICET

La aparición de Espionaje y revolución en el Río de la Plata en el año del centenario de la Semana Trágica es un buen motivo para revisitar el periodo, y en particular el accionar de las agencias de inteligencia en esa etapa.

Se trata de una investigación colectiva sobre unos setenta documentos producidos entre fines de 1918 y mayo de 1919 por una red de espionaje sostenida por las embajadas de Francia, Italia, Inglaterra y Estados Unidos para investigar al movimiento obrero de Argentina y Uruguay y combatir al maximalismo. Las fuentes de la red FABI (por las iniciales de los países participantes) fueron conservadas y halladas un siglo después en los archivos del ministerio de Relaciones Exteriores de Francia. Una red de espionaje de los aliados preexistía en el Río de la Plata, pero orientada a controlar la presencia de agentes y propaganda alemana.

El libro reconstruye los perfiles de los responsables de la red en cada legación diplomática, provee información sobre sus agentes e informantes y sobre el objetivo central de FABI: controlar a los maximalistas, "conglomerado impreciso que abarca a los anarquistas que

1. Hernán Díaz (coord.), Pascual Muñoz, Walter Kopmann, Sabrina Asquini, Lucas Glasman y Cristian Aquino, Espionaje y revolución en el Río de la Plata. Los archivos secretos de una red diplomática de persecución al maximalismo (1918-1919), Buenos Aires, CETHI -Imago Mundi, 2019.

(Archivos, año VIII, $\mathrm{n}^{\circ}$ 15, septiembre de 2019, pp. 163-167) 
utilizan métodos de acción directa, a los socialistas de izquierda y a los rusos que se consideran solidarios con el gobierno revolucionario de su país". ${ }^{2}$ Las centrales obreras quedaron fuera de esta vigilancia, aunque algunas organizaciones sindicales de actividades directamente vinculadas a los intereses angloamericanas fueron objeto de control. Los responsables de la red partían del supuesto de que el movimiento revolucionario no tenía una voluntad independiente, sino que recibian directivas y financiación de Alemania.

El texto coordinado por Hernán Díaz da cuenta de las exageraciones de los informantes con respecto al peligro y a las acciones revolucionarias, de la animadversión hacia la figura de Hipólito Yrigoyen y del foco de atención puesto en los rusos residentes en Argentina y en Uruguay. Con relación a la Semana Trágica, los informes de la red señalan que, aunque existían grupos interesados en promover una revolución, "el movimiento de enero no fue planificado y en cierto modo fue precipitado por los acontecimientos espontáneos de la fábrica Vasena". ${ }^{3}$ Esta interpretación choca con la que sostendría el gobierno argentino y que sería asumida por muchos actores contemporáneos y analistas posteriores, según la cual la Semana Trágica constituyó en efecto un intento revolucionario.

El libro se cierra con un apéndice documental en el que se reproducen informes sobre la Semana Trágica, el periódico en lengua rusa Golos Trudá, informaciones sobre militantes y organizaciones maximalistas y listados de dirigentes y agitadores en Montevideo y Buenos Aires.

Siendo un libro breve y sencillo, Espionaje y revolución es un aporte importante para la comprensión del periodo, y en particular de la coyuntura de la Semana Trágica, permitiendo completar un cuadro que antes se presentaba fragmentario en ciertos aspectos.

Por ejemplo, sabíamos que distintas informaciones, originadas en legaciones argentinas en el exterior o en el cuerpo diplomático extranjero acreditado en Buenos Aires, advertían, en diciembre de 1918, sobre la llegada al país de agitadores rusos que preparaban un complot bolchevique. También teníamos conocimiento de que en sus memorias, el por entonces embajador norteamericano en Buenos Aires Frederick Jessup Stimson afirmaba haber recibido información acerca de la existencia en 1918 y 1919 de un movimiento internacional liderado por el comunismo, que debía estallar simultáneamente en los cinco puertos más importantes para los aliados -Estocolmo, Rotterdam, Liverpool, Nueva

2. Ídem, p. 31.

3. Ídem, p. 62. 
York y Buenos Aires- y cuyos dirigentes eran en su mayoria judios. ${ }^{4}$ Conocemos ahora las fuentes e intencionalidad de esas informaciones.

\section{En los archivos norteamericanos}

En una investigación que desarrollé recientemente en los archivos de Estados Unidos, no encontré evidencia directa de la existencia de FABI (en mis propósitos de pesquisa, formulados previamente a la aparición del libro, ese no era un objetivo), pero sí diversos indicios que en todos los casos parecen confirmar la participación norteamericana en la red.

En primer lugar, tanto en las perspectivas de la inteligencia como en las del Departamento de Estado norteamericano se tendía a emparentar a los movimientos bolcheviques en el mundo con la acción alemana. En los archivos del Departamento de Estado norteamericano y en los del presidente Wilson se constata que, a fines de 1918 y comienzos de 1919, la preocupación norteamericana se centraba en dos temas. Por un lado la revolución soviética, la guerra civil y la intervención occidental en Rusia que la sucedieron y el temor ante la posibilidad de que acontecimientos similares ocurrieran en otras latitudes. El seguimiento de las huelgas en todo el mundo, desde Noruega y Bélgica hasta Cuba o Brasil, del movimiento de dinero y personas proveniente de Rusia y por supuesto de la revolución espartaquista, era permanente en los cables diplomáticos y de inteligencia norteamericanos. Por otro lado, la información se concentraba en las conversaciones de paz en Francia, y en las maniobras alemanas para tratar de obtener una situación más ventajosa. A menudo ambos factores se coaligaban en la mirada estadounidense. Así, por ejemplo, en una comunicación de enero de 1919 se afirmaba que tanto los bolcheviques como el gobierno alemán explicaban el estallido de conflictos sociales en Francia, mientras en los cables diplomáticos relativos a las huelgas de Cuba de enero de 1919 se sostenía que el partido liberal y el gobierno alemán atizaban el conflicto.

El Secretario de Estado Lansing, creyendo o no en la colusión entre bolcheviques y alemanes, explotaba esta acusación, promoviendo para ello la publicación de libelos, como el folleto The German Bolsheviki Conspiration, ${ }^{5}$ que entre otros usos fue enviado a funcionarios rusos del régimen depuesto con fines de propaganda. ${ }^{6}$ No sorprende entonces que en el parte diario de inteligencia que se enviaba al presidente Wilson

4. Frederick Jessup Stimson, My United States, Nueva York y Londres, 1931.

5. War information series. The Committee on Public Information, octubre de 1918.

6. Biblioteca del Congreso de los Estados Unidos, fondo Presidente Woodrow Wilson, rollo de microfilm 471. Telegrama de la inteligencia militar, Christiania, 4 de diciembre de 1918. 
apareciera, en la sección dedicada al bolchevismo, una información que daba cuenta del rumor según el cual se contratarian oficiales alemanes como instructores para el ejército argentino, lo que nos da un indicio acerca de la centralidad de dicha asociación hasta en los más altos niveles del gobierno estadounidense. ${ }^{7}$

Tal como señala el libro Espionaje y revolución..., en las fuentes norteamericanas se constata que los telegramas originados en Buenos Aires con información de inteligencia eran firmados por el agregado militar Alfred Smith, uno de los miembros de la red. Desde fines de 1918 Smith enviaba informaciones acerca del aumento de la conflictividad social en Argentina, señalando que en los conflictos de Rosario y Mendoza se registraba la presencia de agitadores anarquistas y maximalistas. ${ }^{8} \mathrm{Y}$ seria el propio Alfred Smith quien enviaria los partes de inteligencia con los que se informó sobre el devenir de la Semana Trágica.

Igualmente, tal como se afirma en la investigación, existian divergencias interpretativas entre el embajador Frederic Stimson, quien "no era del todo idóneo para las tareas de inteligencia" y las fuentes de inteligencia. ${ }^{9} \mathrm{El}$ embajador señalaba en sus informes la responsabilidad de Hipólito Yrigoyen en los acontecimientos de enero de 1919 -por lo que consideraba una débil actitud frente al movimiento obrero-, pero estaba convencido de encontrarse frente a un complot maximalista. Stimson señalaba como una prueba de la existencia de dicho complot que de los 182 muertos en lo que definía como los "primeros combates del levantamiento", 150 de los cadáveres recogidos por las autoridades en las calles correspondían a judios rusos. ${ }^{10}$ Ese mismo día, en un telegrama a su gobierno, el embajador transmitia las estimaciones oficiales que calculaban las bajas entre los manifestantes en 500 muertos y 550 heridos, pero dos semanas después, en una comunicación del 27 de enero, informaba al Departamento de Estado que el número de muertos en el "levantamiento" era de 1.356 y el de heridos de alrededor de 5.000. ${ }^{11}$

7. Biblioteca del Congreso de los Estados Unidos, fondo Presidente Woodrow Wilson, rollo de microfilm 469. Sumario diario de inteligencia, 4 de abril de 1919.

8. Biblioteca del Congreso de los Estados Unidos, fondo Presidente Woodrow Wilson, rollo de microfilm 471. Partes de inteligencia, telegramas de los días 17 y 30 de diciembre de 1918.

9. Espionaje y revolución..., p. 24.

10. "The part of maximalism in the disturbances of january 9, 10 and 11th, in Buenos Aires and other Places of the Argentine Republic, Enclosure 1 in Despatch n ${ }^{\circ} 7421$ ", del embajador Frederic Stimson al Departamento de Estado, 13 de enero de 1919, en National Archives and Record Administration (EE.UU.) II, Records of the Dept. of State ref. to internal affairs of Argentina, 1910-1929, 835.00/66-216, microcopy $\mathrm{n}^{\circ} 514$, rollo 3 .

11. Telegramas de los dias 13 y 27 de enero de 1919, en NARA II, ídem. 
En contraste, fuentes de inteligencia militar, sin descartar una eventual instigación bolchevique a lo que era considerado no ya un levantamiento sino un estallido, estimaban las víctimas en 800 muertos y 2.000 heridos. ${ }^{12}$ Pocas semanas más tarde, el boletín semanal de inteligencia que recibía el presidente Wilson y las más altas autoridades norteamericanas mostraba lo poco fundado del rumor que atribuía a los rusos la responsabilidad en la agitación de enero, apelando para ello a las cifras acerca de la nacionalidad de los más importantes dirigentes anarquistas que se declararon "maximalistas" de la Argentina, entre los cuales los originarios de Rusia eran solo 8 en un total de $116 .{ }^{13} \mathrm{Sin}$ duda alguna, esa información está extraída del listado de la red FABI que se reproduce entre las páginas 105 a 110 del anexo documental de Espionaje y revolución...

Como se plantea muy acertadamente en ese libro, la transnacionalización de la investigación histórica se corresponde con la internacionalización del espionaje y la vigilancia policial -acompañada con la intromisión de las autoridades diplomáticas extranjeras en la vigilancia de fuerzas políticas locales-y con la internacionalización de las luchas obreras. Esta forma de internacionalización de la investigación supone una amplia colaboración a la que este breve texto quiere resultar un aporte.

12. Biblioteca del Congreso de los Estados Unidos, fondo Presidente Woodrow Wilson, rollo de microfilm 471. Partes de inteligencia, telegrama 1357 del 22 de enero de 1919.

13. Biblioteca del Congreso de los Estados Unidos, fondo Presidente Woodrow Wilson, rollo de microfilm 469. Weekly Inteligence Sumary 91, 22 de febrero de 1919. 